\title{
Níveis de Suplementação com Sal Mineral Proteinado para Novilhos Nelore Terminados em Pastagem no Período de Baixa Produção Forrageira ${ }^{1}$
}

\author{
Fernanda Barros Moreira², Ivanor Nunes do Prado ${ }^{3}$, Ulysses Cecato ${ }^{3}$, Lucia Maria Zeoula ${ }^{3}$, \\ Fabio Yoshimi Wada ${ }^{4}$, Marcelo Shizuo Torii ${ }^{4}$
}

\begin{abstract}
RESUMO - Foram avaliados dois níveis de suplementação com sal mineral proteinado ( 290 e $\left.400 \mathrm{~g}^{\mathrm{an}}{ }^{-1} \cdot \mathrm{dia}^{-1}\right)$, em comparação ao sal mineral, em 90 novilhos Nelore, mantidos em pastagem de grama estrela roxa (Cynodon plectostachyus Pilger) no inverno. O consumo do suplemento foi ajustado pelo teor de cloreto de sódio adicionado à mistura. Quando considerado o período de adaptação (28 dias) na análise estatística, não foi observada diferença no ganho médio diário (GMD) entre os tratamentos, ao passo que, quando desconsiderado, a suplementação com $400 \mathrm{~g} \cdot \mathrm{an}^{-1} \cdot \mathrm{dia}^{-1}$ resultou em maior GMD $\left(0,15 \mathrm{~kg}\right.$. dia $\left.{ }^{-1}\right)$, em comparação aos demais tratamentos $\left(0,06\right.$ e $0,05 \mathrm{~kg} \cdot \mathrm{dia}^{-1}$ para o sal proteinado, com consumo de $290 \mathrm{~g} \cdot \mathrm{an}^{-1} \cdot \mathrm{dia}^{-1}$, e sal mineral, respectivamente). A qualidade e disponibilidade da forragem foram semelhantes entre os tratamentos, com médias de $4366 \mathrm{~kg}$ de matéria seca.ha ${ }^{-1}, 2145 \mathrm{~kg}$ de matéria verde seca.ha ${ }^{-1}$ e $353 \mathrm{~kg}$ de folhas.ha ${ }^{-1}$. Houve redução na proporção de folhas e colmos e aumento na proporção de material morto, em função dos períodos experimentais. Os valores médios para composição química da pastagem foram de 3,5\% de PB, 1,6\% de PB digestível, 48,1\% de FDA e $48,4 \%$ de DIVMS. A pastagem de grama estrela roxa apresentou baixo valor nutritivo entre os meses de maio e outubro, sendo necessária a suplementação protéica para que os animais pudessem manter ou ganhar peso neste período.
\end{abstract}

Palavras-chave: bovinos de corte, cynodon, grama estrela, inverno, proteína bruta, uréia

\section{Levels of Protein and Mineral Salt Supplements for Nelore Steers Finished in Pasture During the Low Grass Production Season}

\begin{abstract}
Two levels of protein and mineral supplements (290 and 400 g.an. ${ }^{-1}$.day ${ }^{-1}$ ) were evaluated and compared with the mineral supplement in 90 Nelore steers on star grass pasture (Cynodon plectostachyus Pilger) during the winter. The supplement intake was ajusted by the concentration of sodium clore into the mixture. Considering the first 28 days (adaptation period) in the statistical analysis, there was no difference in average daily gain (ADG). Taking out this period of adaptation, the ADG was better for the protein and mineral supplement with intake of $400 \mathrm{~g} . \mathrm{an}^{-1}{ }^{-}$.day ${ }^{-1}(0.15 \mathrm{~kg}$ per animal a day), when compared with the other supplements $\left(0.06\right.$ and $0.05 \mathrm{~kg}$ per animal a day, respectively for intake of $290 \mathrm{~g}$. an. ${ }^{-1}$. day ${ }^{-1}$ of protein mineral supplements and mineral salt). The forage quality and availability were similar for the different treatments, with average levels of $4366 \mathrm{~kg}$ dry matter.ha $\mathrm{a}^{-1}, 2145 \mathrm{~kg}$ green dry matter.ha ${ }^{-1}$, and $353 \mathrm{~kg}$ of leaves.ha ${ }^{-1}$. The proportion of leaves and stems were reduced and the dead material proportion rose during the experimental periods. The chemical composition of forage had values of $3.5 \%$ of CP, $1.6 \%$ of digestible CP, $48.1 \%$ of ADF, and $48.4 \%$ of IVDMD. The sta grass pasture presented poor nutritional quality during beetwen the months of may and october, so the protein supplement is necessary to the animals mantain or gain weight during this period.
\end{abstract}

Key Words: beef steers, crude protein, cynodon, stargrass, urea, winter season

\section{Introdução}

A pecuária de corte do Brasil caracteriza-se pela produção extensiva a pasto. $\mathrm{Na}$ maioria das vezes, o sistema apresenta excesso de forragem durante a primavera e o verão e deficiência de forragem no outono e inverno, resultando em estação úmida marcada por ganhos de peso e estação seca, por perdas de peso.
O uso de pastagens diferidas no período da seca tem sido uma alternativa de baixo custo. Contudo, muitas vezes, o que se observa é queda de peso animal, mesmo com excedente de forragem, resultante, principalmente, da queda na qualidade da forragem madura, uma vez que o nível e a digestibilidade da proteína da forragem diminuem com o envelhecimento da planta (Olson et al., 1994).

\footnotetext{
1 Parte da tese de doutorado da primeira autora, apresentada à Universidade Estadual de Maringá.

2 Medica Veterinária, Universidade Estadual de Londrina, bolsista PRODOC/Capes. E.mail: fbmoreira@sercomtel.com.br

3 Professor Doutor do Departamento de Zootecnia, Universidade Estadual de Maringá, Pesquisador do CNPq.

4 Mestrando do Departamento de Zootecnia, Universidade Estadual de Maringá, bolsista da CAPES.
} 
Por isso, o uso de suplementos que complementem a quantidade de proteína necessária para o melhor aproveitamento da forragem disponível pode ser benéfico para o desempenho animal (Del Curto et al., 1990). Suplementos ricos em proteína degradável no rúmen podem levar ao melhor aproveitamento de forragens tropicais, sobretudo quando a relação entre o NDT (nutrientes digestíveis totais) e a PB (proteína bruta) da forragem for maior que 7 (Moore et al., 1999).

Olson et al. (1994) sugerem que a eficiência de síntese de proteína microbiana diminui quando a concentração de amônia ruminal é inferior a $5 \mathrm{mg} / \mathrm{dL}$ de fluido ruminal. Entretanto, a concentração de amônia ruminal em animais submetidos a forragens de baixa qualidade normalmente é igual ou menor que $5 \mathrm{mg} / \mathrm{dL}$ (Beauty et al., 1994), podendo explicar a resposta positiva em desempenho animal quando feita a suplementação em pastagens com proteína de alta degradabilidade no rúmen.

Considerando que o uso da suplementação em pastagens visa proporcionar melhor desempenho animal pela complementação de nutrientes de baixa disponibilidade na pastagem, seria importante o conhecimento do valor nutritivo da forragem. Há muitas informações na literatura sobre a composição química de pastagens (Valadares Filho et al., 2000). No entanto, poucos dados são encontrados em relação à grama estrela roxa (Cynodon plectostachyus Pilger), apesar do uso difundido na região Norte do Paraná (Nabinger et al., 1999).

Neste trabalho, objetivaram-se estudar o efeito da suplementação com dois níveis de ingestão de sal proteinado (290 e 400 g.an. $\left.{ }^{-1} \cdot \mathrm{dia}^{-1}\right)$ sobre o desempenho de novilhos Nelore mantidos em pastagem de grama estrela roxa e avaliar a disponibilidade e a qualidade da pastagem durante o período de baixa produção forrageira.

\section{Material e Métodos}

O experimento foi conduzido na Fazenda Ibicatu, no município de Centenário do Sul, região norte do Paraná. O solo da região é do tipo Latossolo vermelho escuro, de textura média e o clima é classificado como subtropical úmido mesotérmico (SEAB, 1994). As análises foram realizadas no Laboratório de Nutrição Animal da Universidade Estadual de Maringá.

Foram utilizados 90 novilhos Nelore, com peso inicial médio de $390 \mathrm{~kg}$, mantidos em pastagem de grama estrela roxa (Cynodon plectostachyus Pilger.). Quinze dias antes do início do experimento $(29 / 04 / 1999)$, os animais foram vacinados contra febre aftosa e desverminados com vermífugo à base de albendazol. Após 56 dias (09/07/1999), os animais foram novamente desverminados com o mesmo vermífugo. O controle da mosca-do-chifre foi feito pela aplicação de inseticidas a base de cipermetrina e organofosforados, conforme a necessidade.

Os animais foram identificados e distribuídos ao acaso nos seguintes tratamentos: 1. suplementação mineral; 2. suplementação protéica e mineral com consumo médio de 290 g.an. ${ }^{-1}$.dia ${ }^{-1} ; 3$. suplementação protéica e mineral com consumo médio de 400 g.an. ${ }^{-}$ ${ }^{1}$. $\mathrm{dia}^{-1}$. O ajuste do consumo foi determinado pelo teor de cloreto de sódio presente no suplemento. A composição mineral dos suplementos encontra-se na Tabela 1. Os suplementos utilizados foram farelo de soja, milho triturado, uréia e premix mineral (Minerphós ${ }^{\circledR}$ ) de forma a fornecer $40 \%$ de proteína bruta e $1500 \mathrm{kcal}$ de energia metabolizável por kg de MS do suplemento. A distribuição do sal mineral proteinado foi realizada três vezes por semana. $\mathrm{O}$ consumo médio do suplemento foi obtido pela pesagem da quantidade fornecida e das sobras obtidas a cada troca de piquete.

Os animais foram pesados no início do experimento (14/05/1999) e a cada 28 dias, totalizando cinco períodos de 28 dias, entre os meses de maio e outubro. O ganho de peso médio foi avaliado na presença ou ausência de período prévio de adaptação de 28 dias.

Para cada tratamento, foram utilizados dois potreiros com média de 17,6 ha cada, com pastagem cultivada de grama estrela roxa, com 28 dias de ocupação e 28 dias de descanso para cada potreiro. Em cada um havia um bebedouro com capacidade para 4.000 litros e um cocho coberto com 5 metros de comprimento.

Foram utilizados animais reguladores put-andtake, conforme descrito por Mott \& Lucas (1952), com a finalidade de controlar a disponibilidade de forragem por animal dentro dos diferentes tratamentos. O ajuste de lotação animal foi realizado a cada 28 dias, de modo que a oferta de forragem fosse semelhante entre os três tratamentos. A lotação média no período foi de $0,95 \mathrm{UA} / \mathrm{ha}$.

Para estimar a massa de matéria seca dos potreiros, a cada 28 dias 15 amostras de $0,25 \mathrm{~m}^{2}$ por piquete foram cortadas rente ao solo, conforme técnica 
Tabela 1 - Composição do sal mineral (SM) e do sal mineral proteinado (SMP). Níveis de garantia por $\mathrm{kg}$ do produto

Table 1 - Mineral salt (MS) and protein mineral salt (PMS) composition. Levels of guarantee per $\mathrm{kg}$ of product

\begin{tabular}{|c|c|c|c|}
\hline $\begin{array}{l}\text { Elemento } \\
\text { Element }\end{array}$ & $\begin{array}{l}\text { SM } \\
M S\end{array}$ & $\begin{array}{c}\text { SMP } \\
(290 \mathrm{~g} / \mathrm{anim} / \mathrm{d}) \\
P M S\end{array}$ & $\begin{array}{c}\text { SMP } \\
(400 \mathrm{~g} / \mathrm{anim} / \mathrm{d}) \\
P M S\end{array}$ \\
\hline $\begin{array}{l}\text { Fósforo (g) } \\
\text { Phosphorus }\end{array}$ & 80 & 15 & 15 \\
\hline $\begin{array}{l}\text { Cálcio }(\mathrm{g}) \\
\text { Calcium }\end{array}$ & 140 & 56 & 56 \\
\hline $\begin{array}{l}\text { Magnésio (g) } \\
\text { Magnesium }\end{array}$ & 15 & 15 & 15 \\
\hline $\begin{array}{l}\text { Enxofre (g) } \\
\text { Sulfur }\end{array}$ & 20 & 16 & 16 \\
\hline $\begin{array}{l}\text { Sódio }(\mathrm{g}) \\
\text { Sodium }\end{array}$ & 129,50 & 56,00 & 18,50 \\
\hline $\begin{array}{l}\text { Zinco (mg) } \\
\text { Zinc }\end{array}$ & 2000 & 2500 & 2500 \\
\hline $\begin{array}{l}\text { Cobre }(\mathrm{mg}) \\
\text { Cupper }\end{array}$ & 750 & 650 & 650 \\
\hline $\begin{array}{l}\text { Manganês (mg) } \\
\text { Manganese }\end{array}$ & 500 & 1250 & 1250 \\
\hline $\begin{array}{l}\text { Ferro (mg) } \\
\text { Iron }\end{array}$ & 750 & 500 & 500 \\
\hline $\begin{array}{l}\text { Cobalto (mg) } \\
\text { Cobalt }\end{array}$ & 40 & 25 & 25 \\
\hline $\begin{array}{l}\text { Iodo }(\mathrm{mg}) \\
\text { Iodine }\end{array}$ & 40 & 40 & 40 \\
\hline $\begin{array}{l}\text { Selênio (mg) } \\
\text { Selenium }\end{array}$ & 15 & 15 & 15 \\
\hline $\begin{array}{l}\text { Flúor }(\mathrm{mg}) \\
\text { Magnesium }\end{array}$ & 800 & 150 & 150 \\
\hline $\begin{array}{l}\text { Antioxidante }(\mathrm{mg}) \\
\text { Antioxidant }\end{array}$ & - & 2000 & 2000 \\
\hline $\begin{array}{l}\text { Niacina (mg) } \\
\text { Niacin }\end{array}$ & - & 497,50 & 497,50 \\
\hline $\begin{array}{l}\text { Vit. A(U.I.) } \\
\text { Vit. D3 (U.I.) }\end{array}$ & - & $\begin{array}{r}250000 \\
83500\end{array}$ & $\begin{array}{r}250000 \\
83500\end{array}$ \\
\hline Vit.E(mg) & - & 84 & 84 \\
\hline
\end{tabular}

descrita por Houlderbaun \& Sollenberg (1992). Posteriormente, foram divididas em duas porções, das quais uma foi separada em lâmina foliar, colmo e material morto, enquanto a outra não sofreu divisão, preservando todos os componentes da planta. As duas porções foram secas em estufa a $55^{\circ} \mathrm{C}$ por $72 \mathrm{~h}$ e moídas para análises posteriores. A massa de matéria seca de folhas, de colmo e de material morto por potreiro foi avaliada ao longo dos cinco períodos do experimento.

Para avaliar a composição química da forragem foram determinados os teores de matéria seca, de matéria orgânica, de proteína bruta, de proteína bruta digestível e de fibra detergente ácido, conforme descrito por Silva (1990). Os teores de proteína digestíveis foram obtidos subtraindo-se a proteína insolúvel em detergente ácido do teor de proteína bruta, conforme metodologia de Van Soest (1994).

A digestibilidade in vitro da matéria seca foi determinada pela metodologia de Tilley \& Terry (1963), adaptada para o uso do rúmen artificial, desenvolvida por $\mathrm{ANKOM}^{\circledR}$, conforme descrito por Holden (1999). O teor de NDT foi considerado igual a digestibilidade in vitro da matéria orgânica, sendo esta estimada pela fórmula: DIVMO $=-0,664+$ 1,032DIVMS (Moore et al., 1999).

O consumo da forragem foi estimado pela fórmula: consumo $=\mathrm{PV}^{0,75}\left(0,1493 \mathrm{ELm}-0,046 \mathrm{ELm}^{2}-0,0196\right)$, em que PV é o peso em jejum e ELm, a energia líquida de mantença da forragem (NRC, 1996).

O delineamento experimental foi inteiramente casualizado, com 30 repetições para cada tratamento. A análise estatística e a correlação entre as variáveis foram realizadas utilizando-se do Sistema de Análises Estatísticas e Genéticas (SAEG). Para comparação entre as médias utilizou-se o teste de Tukey a $5 \%$ de probabilidade.

\section{Resultados e Discussão}

Não foi observada diferença $(\mathrm{P}>0,05)$ no peso vivo final dos animais para os diferentes tratamentos (Tabela 2). O ganho médio diário (GMD), obtido durante todo o período experimental (GMD1 incluindo o período de adaptação), não apresentou diferenças $(\mathrm{P}>0,05)$ entre os tratamentos. Por outro lado, considerando o período com exclusão dos primeiros 28 dias de adaptação (GMD2), o maior nível de ingestão do sal mineral proteinado (400 g.an.${ }^{-1}$. dia ${ }^{-1}$ ) resultou em maior $(\mathrm{P}<0,05)$ GMD. Não foi observada diferença $(\mathrm{P}>0,05)$ para o GMD entre o sal mineral e o menor nível de ingestão de sal mineral proteinado $\left(290\right.$ g.an. $\left.{ }^{-1} \cdot \mathrm{dia}^{-1}\right)$.

Durante os primeiros 28 dias experimentais (de 14/05 a 11/06 de 1999), observou-se menor GMD para os animais suplementados com sal mineral proteinado. O GMD observado neste período foi de 1,$02 ; 0,79$ e $0,67 \mathrm{~kg} \cdot \mathrm{an}^{-1} \cdot \mathrm{dia}^{-1}$ para os tratamentos com sal mineral e sal mineral proteinado $(290$ e 400 g.an. ${ }^{-1} \cdot$ dia $^{-1}$, respectivamente). Este menor GMD poderia ser decorrente do uso de uréia no suplemento protéico. O período de adaptação à uréia pode variar de duas a seis semanas, sendo necessário maior 
Tabela 2 - Peso vivo médio inicial (PVI), peso vivo médio final (PVF), ganho médio diário com inclusão (GMD1) ou exclusão (GMD2) do período de adaptação, consumo médio diário do suplemento (CMS), consumo médio diário da forragem (CMF) e ganho de peso (GP) por hectare

Table 2 - Initial body weight (IBW), final body weight (FBW), average daily gain with (ADG1) or without (ADG2) adaptation period, average daily supplement intake (ASI), average daily forage intake (AFI) and body weight gain (BWG) per ha

\begin{tabular}{|c|c|c|c|c|}
\hline & $\mathrm{SM}^{1}$ & $\mathrm{SPI}^{2}$ & $\mathrm{SPII}^{3}$ & $\mathrm{CV}^{4}$ \\
\hline$\overline{\mathrm{PVI}(\mathrm{kg})}$ & 390 & 396 & 393 & 8,68 \\
\hline$I B W(\mathrm{~kg})$ & & & & \\
\hline PVF (kg) & 425 & 424 & 428 & 7,92 \\
\hline $\begin{array}{l}F B W(\mathrm{~kg}) \\
\mathrm{GMD} 1^{5}\left(\mathrm{~kg} \cdot \mathrm{dia}^{-1}\right) \\
A D G 1^{5}\left(\mathrm{~kg} \cdot d a y^{-1}\right)\end{array}$ & 0,25 & 0,20 & 0,25 & 40,76 \\
\hline $\begin{array}{l}\mathrm{GMD}^{6}{ }^{6}\left(\mathrm{~kg} \cdot \mathrm{dia}^{-1}\right) \\
A D G 2^{6}\left(\mathrm{~kg}^{-} \cdot \mathrm{day}^{-1}\right)\end{array}$ & $0,06 \mathrm{~b}$ & $0,05 b$ & $0,15 \mathrm{a}$ & 127,36 \\
\hline $\begin{array}{l}\left.\text { CMS (g.an. }{ }^{-1} \cdot \text { dia }^{-1}\right) \\
\left.\text { ASI (g.an. } .^{-1} d a y^{-1}\right)\end{array}$ & 27 & 293 & 397 & - \\
\hline CMF (\% do PV) & 1,67 & 1,73 & 1,71 & - \\
\hline $\begin{array}{l}\mathrm{GP}\left(\mathrm{kg} \mathrm{PV} \cdot \mathrm{ha}^{-1}\right) \\
B W G\left(k g \cdot h a^{-1}\right)\end{array}$ & 37,46 & 28,86 & 34,67 & - \\
\hline
\end{tabular}

1SM: suplementação mineral; ${ }^{2} \mathrm{SMPI}$ suplementação mineral e protéica, consumo de 290 g.an. ${ }^{-1} \cdot$ dia $^{-1}$; ${ }^{3}$ SMPII: suplementação mineral e protéica, consumo de 400 g.an.${ }^{-1}$.dia ${ }^{-1} .{ }^{4}$ Coeficiente de variação; ${ }^{5}$ GMD1: período de 14/05/1999 a 01/10/1999 ${ }^{6}$ GMD2: período de 11/06/1999 a 01/10/1999. Letras diferentes na mesma linha são diferentes pelo teste de Tukey $(P<0,05)$.

${ }^{1}$ SM: mineral supplementation; ${ }^{2}$ SMPI: protein and mineral supplementation, intake of 290 g.an..$^{-1} \cdot$ day $^{-1}:{ }^{3}$ SMPII: protein and mineral supplementation, intake of $400 \mathrm{~g}$. an.$^{-1}$. day ${ }^{-1} \cdot{ }^{4} \mathrm{CV}$ : variation coeficient; ${ }^{5} \mathrm{ADG} 1$ : period from $05 /$ 14/1999 to 10/01/1999; ${ }^{6} A D G 2$ : period from 06/11/1999 to $10 / 01 / 1999$. Different letter in the same line are different by Tukey test $(P<0,05)$.

período para animais que estavam consumindo dietas com baixos níveis de proteína (Huber, 1994).

Os mecanismos envolvidos no processo de adaptação à uréia não são claros, mas provavelmente estejam relacionados ao aumento na capacidade de o fígado sintetizar uréia a partir da amônia absorvida, promovendo a reciclagem da uréia pela saliva ou a excreção do excesso pela urina. Quando o fígado não transforma toda amônia em uréia, aumentam os níveis de amônia na circulação sangüínea, o que pode acarretar alterações no metabolismo energético do animal. Boin (1994) levantou a hipótese de que a presença da amônia em nível celular promove o esgotamento do $\alpha$-cetoglutarato para a formação do glutamato, determinando a inibição do ciclo do ácido tricarboxílico, interrompendo o metabolismo energético e a síntese de ATP. No fígado, o ciclo da uréia também utiliza energia e oxaloacetato para formação de uréia e o resultado final é a queda na produção de ATP para a síntese corporal. Aumento nos níveis de amônia circulante também pode determinar diminuição do consumo voluntário (Forbes, 1995) e, conseqüentemente, do desempenho animal.

Zanetti et al. (2000), trabalhando com novilhos de $200 \mathrm{~kg}$ de peso vivo, durante o período do inverno, verificaram GMD de $0,36 \mathrm{~kg} \cdot \mathrm{dia}^{-1}$ para animais suplementados com sal proteinado e perda média de $0,10 \mathrm{~kg} \cdot \mathrm{dia}^{-1}$ para os que receberam apenas sal mineral. O GMD obtido por esses autores foi maior que o GMD alcançado neste experimento, provavelmente em decorrência do maior consumo de suplemento (650 g.an. ${ }^{-1} \cdot \mathrm{dia}^{-1}$ ). Melhor desempenho para novilhos suplementados no período do inverno também foi observado por Euclides et al. (2001), com $0,66 \mathrm{~kg}$ de GMD em animais suplementados com $3,30 \mathrm{~kg} \cdot \mathrm{dia}^{-1}$ do suplemento protéico, enquanto animais suplementados apenas com sal mineral apresentaram perda de $0,13 \mathrm{~kg} \cdot \mathrm{dia}^{-1}$.

Por outro lado, o GP.ha ${ }^{-1}$ foi semelhante para os três tratamentos, mas foram baixos, com valores próximos aos $34 \mathrm{~kg}$ (Tabela 2). Deve-se considerar que foi analisado apenas o período do inverno, quando a produção e a qualidade forrageira diminuem (Tabela 4), reduzindo o desempenho animal e o ganho por área. Todavia, os valores observados foram semelhantes aos descritos pela FNP (2001), para sistemas extensivos de produção em pastagens, no período de baixa produção forrageira.

A disponibilidade de matéria seca (folha + colmo + matéria morta), matéria verde seca (folha + colmo) e de folhas foi semelhante para os três tratamentos (Tabela 3). Portanto, as possíveis diferenças no desempenho animal entre os tratamentos, em função de cada período, não foram decorrentes de diferenças na disponibilidade da forragem oferecida.

A disponibilidade total de matéria seca, durante todo o período experimental, esteve acima dos $2000 \mathrm{~kg} \cdot \mathrm{ha}^{-1}$, valor considerado por Minson (1990) como o mínimo para que a disponibilidade não ocasione redução no consumo da pastagem. Da mesma forma, a disponibilidade de matéria verde seca, também situou-se acima dos $2000 \mathrm{~kg} \cdot \mathrm{ha}^{-1}$. Houve grande diferença na disponibilidade de matéria verde seca e disponibilidade de matéria seca total, em razão da elevada proporção de material morto na pastagem. Vale salientar que, no final do período experimental, aproximadamente $60 \%$ da pastagem eram compostos por matéria morta. 


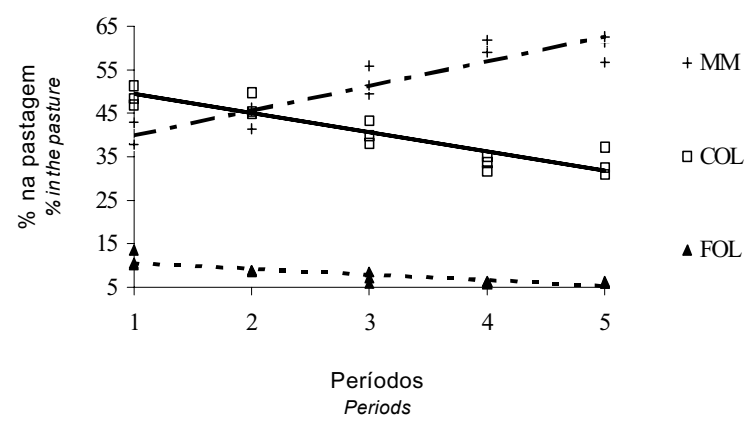

Figura 1 - Proporção de folha (FOL), colmo (COL) e matéria morta (MM) na pastagem nos cinco períodos experimentais, entre maio e outubro de 1999.

Figure 1 - Leaf (FOL), stem (COL) and dead material (MM) proportion in the pasture in five experimental periods from May to October 1999.

A disponibilidade de lâminas foliares foi em torno de $350 \mathrm{~kg} \mathrm{ha}^{-1}$ (Tabela 3). No início do período experimental, a disponibilidade de lâminas foliares foi de $550 \mathrm{~kg} \cdot \mathrm{ha}^{-1} \mathrm{e}$ no final, de $230 \mathrm{~kg} \cdot \mathrm{ha}^{-1}$. A baixa disponibilidade de lâminas foliares resultou de sua baixa proporção no perfil da pastagem $(11 \% \mathrm{em}$ 14/05/1999 e 6\% em 01/10/1999 (Figura 1).

Houve redução linear na proporção de folhas $\left(\mathrm{y}=11,9-1,32 \mathrm{x} ; \mathrm{R}^{2}=0,74\right)$ e de colmos $(\mathrm{y}=53,84-$ $\left.4,39 \mathrm{x} ; \mathrm{R}^{2}=0,85\right)$ e aumento linear na proporção de matéria morta $\left(\mathrm{y}=34,25+5,71 \mathrm{x} ; \mathrm{R}^{2}=0,88\right)$ com o desenvolvimento da planta (Figura 1). A diminuição progressiva na proporção de folhas e colmos decorreu da constante retirada destes elementos pelo pastoreio animal e do baixo acúmulo de matéria seca da forragem obtido no período, em virtude das condições climáticas adversas, o que prejudicou o rebrote da pastagem. Bortolo et al. (2001), trabalhando com Coastcross-1 pastejada por ovinos, também observaram redução linear na disponibilidade e na proporção de folhas na pastagem.

Os teores de proteína bruta (PB), de proteína bruta digestível (PBD) e de fibra em detergente ácido (FDA) foram semelhantes para os três tratamentos (Tabela 4). Os teores de PB das pastagens, durante todo o período experimental, estiveram abaixo do valor mínimo (7\% na MS) preconizado por Van Soest (1994) para que não haja prejuízo na utilização da forragem por parte dos microrganismos ruminais. Além dos teores de PB abaixo dos níveis mínimos, parte do nitrogênio esteve na forma não-disponível para os
Tabela 3 - Disponibilidade de matéria seca total (MS), matéria verde seca (MVS) e de lâminas foliares (FOL) por hectare na pastagem para os diferentes tratamentos $\left(\mathrm{kg}^{\mathrm{h}} \mathrm{ha}^{-1}\right)$

Table 3 - Total dry matter (DM), green dry matter (GDM) and lamina (LAM) availability per hectare in grassland for the different treatments (kg.ha-1)

\begin{tabular}{lccc}
\hline & SM $^{1}$ & SPI $^{2}$ & SPII $^{3}$ \\
\hline MS (DM) & 4505 & 4320 & 4273 \\
MVS (GDM) & 2289 & 2118 & 2028 \\
FOL $($ LAM) & 357 & 345 & 356 \\
\hline
\end{tabular}

${ }^{1} \mathrm{SM}$ : suplementação mineral; ${ }^{2} \mathrm{SMPI}$ : suplementação mineral e protéica, consumo de 290 g.an.$^{-1} \cdot$ dia $^{-1} ;{ }^{3}$ SMPII: suplementação mineral e protéica, consumo de 400 g.an. ${ }^{-1} \cdot$ dia $^{-1}$.

${ }^{1}$ SM: mineral supplementation; ${ }^{2}$ SMPI: protein and mineral supplementation, intake of $290 \mathrm{~g} \cdot \mathrm{an}^{-1} \cdot \mathrm{dia}^{-1}{ }^{3}{ }^{3} \mathrm{SMPII}$ : protein and mineral supplementation, intake of $400 \mathrm{~g} \cdot \mathrm{an}^{-1} \cdot \mathrm{dia}^{-1}$

Tabela 4 - Teores de matéria orgânica (MO), de proteína bruta (PB), de proteína bruta digestível (PBD) e de fibra em detergente ácido (FDA) da forragem e das frações folha e colmo (\% na matéria seca)

Table 4 - Organic matter (OM), crude protein (CP), digestible crude protein (DCP) and acid detergent fiber (ADF) of the forage and leaf and stem fraction (\% in dry matter)

\section{Análise bromatológica da forragem}

Bromatological analysis of forage

$\begin{array}{lcccc}\text { Tratamentos } & \text { MO } & \text { PB } & \text { PBD } & \text { FDA } \\ \text { Treatment } & O M & C P & D C P & A D F \\ \text { SM }^{1} & 94,61 & 3,40 & 1,80 & 48,20 \\ \text { SMPI }^{2} & 94,19 & 3,60 & 1,60 & 48,00 \\ \text { SMPII }^{3} & 94,03 & 3,40 & 1,40 & 48,00\end{array}$

\begin{tabular}{lcccc} 
& \multicolumn{4}{c}{ Análise bromatológica das frações folha e colmo } \\
& Bromatological analysis of leaf and stem fraction \\
SM $^{1}$ & 94,03 & 4,30 & 3,08 & 44,42 \\
SMPI $^{2}$ & 93,95 & 4,34 & 3,04 & 44,66 \\
SMPII $^{3}$ & 93,42 & 4,40 & 3,16 & 43,32 \\
\hline
\end{tabular}

${ }^{1} \mathrm{SM}$ : suplementação mineral; ${ }^{2} \mathrm{SMPI}:$ suplementação mineral e protéica, consumo de $290 \mathrm{~g} \cdot \mathrm{an}^{-1} \cdot \mathrm{dia}^{-1} ;{ }^{3} \mathrm{SMPII}$ : suplementação mineral e protéica, consumo de 400 g.an. ${ }^{-1} \cdot$ dia $^{-1}$.

${ }^{1}$ SM: mineral supplementation; ${ }^{2}$ SMPI: protein and mineral supplementation, intake of 290 g.an. ${ }^{-1} \cdot$ day $^{-1} .0,07 \%$ of body weight; ${ }^{3}$ SMPIl: protein and mineral supplementation, intake of $400 \mathrm{~g} \cdot \mathrm{an}^{-1} \cdot \mathrm{day}^{-1}$.

microrganismos (nitrogênio insolúvel em detergente ácido - NIDA), o que reduziu ainda mais os teores de nitrogênio que seriam aproveitados pelos microrganismos do rúmen. Altos teores de FDA e NIDA são decorrentes da maturidade da planta e ocasionam aumento no conteúdo de parede celular, constituída por hemicelulose, celulose e lignina (Reis et al., 1997). 
$\mathrm{O}$ teor de $\mathrm{PB}$ da matéria verde seca (folha $\mathrm{e}$ colmo) também foi inferior a 7\%/MS. Portanto, mesmo havendo pastejo seletivo, por parte dos animais, evitando o consumo de matéria morta, o teor de PB do material ingerido também foi inferior ao mínimo (7\%/MS) estabelecido (Van Soest, 1994), o que justifica o melhor resultado com a suplementação protéica, uma vez que a adição de proteína degradável no rúmen, por meio do suplemento, fez com que elevasse a ingestão de nitrogênio, favorecendo a digestão da forragem.

Os teores de PB das folhas, dos colmos e do material morto se mantiveram constantes ao longo do período experimental e foram maiores para as folhas (aproximadamente 8\%) e menores para colmos e material morto (4 e 3\%, respectivamente) (Figura 2). Nota-se que os teores de PB da pastagem de grama estrela podem se manter em níveis mais elevados, caso haja diferimento desta pastagem com maiores proporções de folhas, de modo que o teor de PB da planta possa ser elevado pela maior porcentagem de folhas no relvado. Esta pode ser uma prática de manejo a ser adotada para que se minimizem as perdas ocorridas no período de baixa produção forrageira.

A digestibilidade in vitro da matéria seca total foi semelhante para os três tratamentos (Tabela 5). O valor obtido foi baixo, em função do período analisado (época da seca), quando o acúmulo de matéria seca da pastagem diminui e cresce a proporção de material morto. Com o avanço da maturidade da planta, o

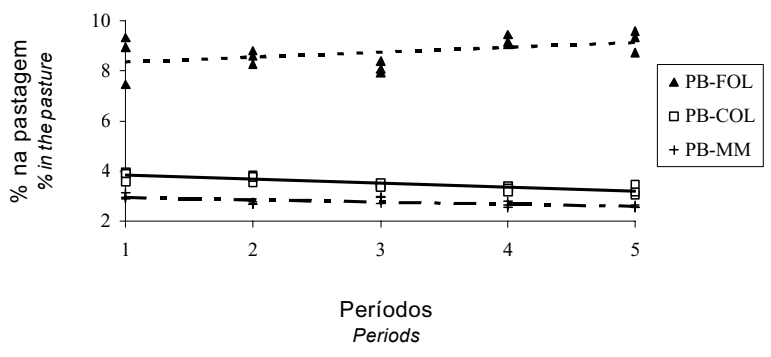

Figura 2 - Porcentagem de proteína bruta da folha (PBFOL), do colmo (PB-COL) e do material morto (PB-MM) na matéria seca (MS) da pastagem durante o período experimental, entre maio e outubro de 1999

Figure 2 - Crude protein percentage of leaf (PB-FOL), stem (PB-COL) and dead material (PB-MM) in dry matter (DM) of the pasture during the experimental periods from May to October of 1999. conteúdo de parede celular, sobretudo a lignina, aumenta, resultando em redução da digestibilidade da forragem (Dove, 1998).

Consta, na Tabela 5, a relação entre o teor de NDT e de PB da matéria seca da forragem. Esta relação esteve acima de 7 , e segundo Moore et al. (1999), quando a relação NDT:PB está acima de 7, há déficit de proteína em relação à energia. Neste caso, pequenas quantidades de proteína possibilitariam aumento no consumo da forragem e, conseqüentemente, melhoria no desempenho animal. Portanto, a proteína fornecida pelo sal mineral proteinado com consumo de 400 g.an. ${ }^{-1}$.dia ${ }^{-1}$ promoveu redução da relação NDT:PB da dieta, o que resultou em melhor GMD para os animais suplementados.

A disponibilidade e a composição química da forragem podem influenciar o desempenho animal (Tabela 6). Houve correlação positiva entre disponibilidade de matéria seca, de matéria verde seca e de folhas com o desempenho animal. Maior disponibilidade de forragem verde favorece a seletividade e diminui o tempo utilizado para pastejo (Euclides et al., 1999), possibilitando melhor desempenho animal.

$\mathrm{O}$ acúmulo de material morto na pastagem apresentou correlação negativa com o desempenho animal, possivelmente em razão da baixa qualidade nutricional deste material. A PB da folha apresentou baixa correlação com o desempenho animal, provavelmente porque foi avaliado apenas o período

Tabela 5 - Digestibilidade in vitro da matéria seca (DIVMS), nutrientes digestíveis totais (NDT) e relação entre o NDT e a proteína bruta da forragem ( $\%$ na matéria seca)

Table 5 - In vitro dry matter digestibility (IVDMD), total digestive nutrients (TDN) and relationship between TDN and crude protein of the forage $(\%$ in dry matter)

\begin{tabular}{lccc}
\hline & SM $^{1}$ & SMPI $^{2}$ & SMPII $^{3}$ \\
\hline DIVMS (IVDMD) & 47,08 & 48,88 & 49,15 \\
NDT (TDN) & 47,86 & 49,71 & 50,31 \\
NDT:PB (TDN:CP) & 13,85 & 13,58 & 14,46 \\
\hline
\end{tabular}

${ }^{1} \mathrm{SM}$ : suplementação mineral; ${ }^{2} \mathrm{SMPI}$ : suplementação mineral e protéica, consumo de 290 g.an. ${ }^{-1} \cdot$ dia $^{-1} ;{ }^{3}$ SMPII: suplementação mineral e protéica, consumo de 400 g.an. ${ }^{-1} \cdot$ dia $^{-1}$.

${ }^{1}$ SM: mineral supplementation; ${ }^{2}$ SMPI: protein and mineral supplementation, intake of 290 g.an. ${ }^{-1}$.day ${ }^{-1}$; ${ }^{3}$ SMPII: protein and mineral supplementation, intake of 400 g.an.$^{-1} \cdot$ day $^{-1}$. 
Tabela 6 - Correlação de Pearson entre o ganho médio diário (GMD) e algumas características da pastagem Table 6 - Pearson correlation among average daily gain (ADG) and some pasture characteristics

\begin{tabular}{|c|c|c|c|c|c|c|c|c|c|}
\hline & $\begin{array}{l}\text { MS/ha }{ }^{1} \\
D M / h a^{1}\end{array}$ & $\begin{array}{l}\text { MVS/ha } 2 \\
G D M / h a^{2}\end{array}$ & $\begin{array}{l}\mathrm{F} / \mathrm{ha} \mathrm{a}^{3} \\
L / h a^{3}\end{array}$ & $\begin{array}{l}\% \mathrm{~F}^{4} \\
\% L^{4}\end{array}$ & $\begin{array}{l}\% \mathrm{C}^{5} \\
\% S^{5}\end{array}$ & $\begin{array}{c}\% \mathrm{MM}^{6} \\
\% D M^{6}\end{array}$ & $\begin{array}{l}\mathrm{PB}-\mathrm{F}^{7} \\
C P-L^{7}\end{array}$ & $\begin{array}{c}\text { PB-C } \\
C P-S^{8}\end{array}$ & $\begin{array}{c}\text { PB-MM }^{9} \\
C P-D M^{9}\end{array}$ \\
\hline GMD & $0,50 *$ & $0,39 *$ & $0,42 *$ & $0,35 *$ & $0,24 *$ & $-0,28^{*}$ & 0,07 & $0,31 *$ & $0,53 *$ \\
\hline
\end{tabular}

$A D G$

${ }^{1}$ Disponibilidade de matéria seca (folhas + colmos + matéria morta) por hectare; ${ }^{2}$ Disponibilidade de matéria verde seca (folhas + colmos) por hectare; ${ }^{3}$ Disponibilidade de folhas por hectare; ${ }^{4}$ Porcentagem de folhas; ${ }^{5}$ Porcentagem de colmos; ${ }^{6}$ Porcentagem de material morto; ${ }^{7}$ Proteína bruta da folha; ${ }^{8}$ Proteína bruta dos colmos; 9 Proteína bruta da matéria morta; * $P<0,01$.

${ }^{1}$ Dry matter availability (leaves, stems and dead material) per hectare; ${ }^{2}$ Green dry matter availability (leaves and stems) per hectare; ${ }^{3}$ Leaves availability per hectare; ${ }^{4}$ Leaves porcentage; ${ }^{5}$ Stems porcentage; ${ }^{6}$ Dead material porcentage; ${ }^{7}$ Leaves crude protein; ${ }^{8}$ Stems crude protein; ${ }^{9}$ Dead material crude protein. ${ }^{*} P<0.01$.

de inverno e as folhas tiveram pouca participação na dieta animal, em razão de sua baixa proporção na pastagem. No entanto, a PB do colmo e do material morto apresentou alta correlação com o desempenho animal, uma vez que houve maior participação destes componentes na dieta do animal.

\section{Conclusões}

O maior nível de suplementação com sal mineral proteinado (400 g.an. ${ }^{-1}$.dia ${ }^{-1}$.) resultou em maior ganho médio diário quando comparado ao sal mineral ou ao sal proteinado com ingestão de 290 g.an. ${ }^{-1}$.dia ${ }^{-1}$.

A matéria seca da pastagem de grama estrela roxa apresenta baixo valor nutritivo no período do inverno, sendo necessária a suplementação protéica para que os animais possam manter ou ganhar peso neste período.

\section{Agradecimento}

À MINERPHÓS Ltda, por disponibilizar os suplementos mineral e protéico para realização deste experimento. Da mesma forma, ao proprietário da Fazenda Ibicatu, Sr. Armando Vieira Moreira, pela concessão dos animais, da propriedade e de recursos humanos para realização do experimento.

\section{Literatura Citada}

BEAUTY, J.L.; COCHRAN, R.C.; LINTZENICH, B.A. et al. Effect of frequency of supplementation and protein concentration in supplements on performance and digestion characteristics of beef cattle consuming low-quality forages. Journal of Animal Science, v.72, n.9, p.2475-2486, 1994.

BOIN, C. Efeitos desfavoráveis da utilização da uréia. In: SIMPÓSIO SOBRE NUTRIÇÃO DE BOVINOS, 2., 1994, Piracicaba. Anais... Piracicaba: Fundação de Estudos Agrários Luiz de Queiroz, 1994. p.19-62.

R. Bras. Zootec., v.33, n.6, p.1814-1821, 2004 (Supl. 1)
BORTOLO, M.; CECATO, U.; MARTINS, E.N. et al. Avaliação de uma pastagem de Coastcross-1 (Cynodon dactylon (L.) Pers) sob diferentes níveis de matéria seca residual. Revista Brasileira de Zootecnia, v.30, n.3, p.627-635, 2001.

DEL CURTO, T.; COCHRAN, R.C.; HAERMAN, D.L. et al. Supplementation of dormant tall grass-prairie forage: I. Influence of varying supplemental protein and (or) energy levels on forage utilization characteristics of beef steers in confinement. Journal of Animal Science, v.68, n.2, p.515-531, 1990.

DOVE, $\mathrm{H}$. The ruminant, the rumen and the pasture resource: nutrient interactions in the grazing animal. In: HODGSON, J.; ILLIUS, A.W. (Eds.) The ecology and management of grazing systems. 2.ed. London: CAB International, 1998. 466p.

EUCLIDES, V.P.B.; THIAGO, L.R.L.S.; MACEDO, M.C.M.; et al. Consumo voluntário de forragem de três cultivares de Panicum maximum sob pastejo. Revista Brasileira de Zootecnia, v.28, n.6, p.1177-1185, 1999.

EUCLIDES, V.P.B.; EUCLIDES FILHO, K.; COSTA, F.P. et al. Desempenho de novilhos F1s angus-nelore em pastagens de Brachiaria decumbens submetidos a diferentes regimes alimentares. Revista Brasileira de Zootecnia, v.30, n.2, p.470-481, 2001.

FNP - Anuário da pecuária brasileira. São Paulo, SP: ANUALPEC, 2001. 359p.

FORBES, J.M. Voluntary food intake and diet selection in farm animals. United Kingdom: $\mathrm{CAB}$ Internacional, 1995. 532p.

HOLDEN, L.A. Comparison of methods of in vitro dry matter digestibility for ten feeds. Journal of Dairy Science, v.82, n. 8, p.1791-1794, 1999.

HOLDERBAUN, J.F.; SOLlEnBERG, K.H. Canopy structure and nutritive value of limpograss pastures during mid-summer to early autumn. Agronomy Journal, v.84, n.1, p.11-16, 1992.

HUBER, J.T. Uréia ao nível de rúmen. In: SIMPÓSIO SOBRE NUTRIÇÃO DE BOVINOS, 2., 1994, Piracicaba. Anais... Piracicaba: Fundação de Estudos Agrários Luiz de Queiroz, 1994. p.1-17.

MINSON, D.J. Forage in ruminant nutrition. San Diego: Academic Press, Inc., 1990. 483p.

MOORE, J.E.; BRANT, M.H.; KUNKLE, W.E. et al. Effects of supplementation on voluntary forage intake, diet digestibility, and animal performance. Journal of Animal Science, v.77, suppl. 2/J, p.122-135, 1999.

MOTT, G.O.; LUCAS, H.L. The design, conduct and interpretation of grazing trials on cultivated an improved pastures. In: INTERNATIONAL GRASSLAND 
CONGRess, 6, 1952. Pennsylvania. Proceedings... Pennsylvania: State College Press, 1952. p.1380-1385.

NABINGER, C.; MARASCHIN, G.E.; MORAES, A. Pasture related problems in beef cattle production in southern brazil. In: GRASSLAND ECOPHYSIOLOGY AND GRAZING ECOLOGY, 1999, Curitiba. Anais... Curitiba: Universidade Federal do Paraná, 1999. p.23-48.

NATIONAL RESEARCH COUNCIL - NRC. Nutrient requirement of beef cattle. 7.ed. Washington, D.C.: 1996. 242p.

OLSON, K.C.; CATON, J.S.; KIRBY, D.R. et al. Influence of yeast culture supplementation and advancing season on steers grazing mixed-grass prairie in the northern great plains: II. Ruminal fermentation, site of digestion and microbial efficiency. Journal of Animal Science, v.72, n.8, p.2158-2170, 1994.

REIS, R.A.; RODRIGUES, L.R.A.; PEREIRA, J.R.A. A suplementação como estratégia de manejo de pastagem. In: SIMPÓSIO SOBRE MANEJO DA PASTAGEM, 13., 1996, Piracicaba. Anais... Piracicaba: Fundação de Estudos Agrários Luiz de Queiroz, 1997. p.123-150.

SECRETARIA DA AGRICULTURA E DO ABASTECIMENTO - SEAB. Manual técnico do subprograma de manejo e conservação do solo. Curitiba: 1994. 372p.
SILVA, D.J. Análise de alimentos (métodos químicos e biológicos. 2.ed. Viçosa, MG: Universidade Federal de Viçosa, 1990. 165p.

TILLEY, J.M.A.; TERRY, R.A. A two-stage technique for the in vitro digestion of forage crops. Journal British of Grassland Society, v.18, p.104-111, 1963.

UNIVERSIDADE FEDERAL DE VICCOSA - UFV. SAEG Sistema para análises estatísticas e genéticas. Versão 7.1. Viçosa, MG: 1997. 150p. (Manual do usuário)

VALADARES FILHO, S.C. Nutrição, avaliação de alimentos e tabelas de composição de alimentos para bovinos. In: REUNIÃO ANUAL DA SOCIEDADE BRASILEIRA DE ZOOTECNIA, 37., 2000, Viçosa, MG. Anais... Viçosa, MG: Sociedade Brasileira de Zootecnia, 2000. p.267-339.

Van SOEST, P.J. Nutritional ecology of the ruminant. 2.ed. New York: Cornell University Press, 1994. 476p.

ZANETTI, M.A.; RESENDE, J.M.L.; SCHALCH, F. et al. Desempenho de novilhos consumindo suplemento mineral proteinado convencional ou com uréia. Revista Brasileira Zootecnia, v.29, n.3, p.935-939, 2000.

Recebido em: 17/02/03

Aceito em: 30/03/04 